in vivo $33: 2273-2280(2019)$

doi:10.21873/invivo.11733

\title{
Use of Droplet Digital Polymerase Chain Reaction for Detecting Minimal Residual Disease: A Prospective Multi-Institutional Study
}

\author{
HYUNKYUNG PARK ${ }^{1,2^{*}}$, DONG-YEOP SHIN ${ }^{1 *}$, INHO KIM $^{1 \dagger}$, SANG-KYUN SOHN $^{3 \dagger}$, \\ YOUNGIL KOH ${ }^{1}$, JE-HWAN LEE ${ }^{4}$, KYOO-HYUNG LEE ${ }^{4}$, DAE-YOUNG KIM ${ }^{4}$, \\ HYEONG-JOON KIM ${ }^{5}$, JAE-SOOK AHN ${ }^{5}$, JEONG-OK LEE ${ }^{6}$, SOO-MEE BANG ${ }^{6}$, \\ JUNE-WON CHEONG ${ }^{7}$, SANG-GON PARK $^{8}$, SEONYANG PARK $^{1,9}$, YOO JIN LEE ${ }^{3}$ and SEO-YEON AHN ${ }^{5}$ \\ ${ }^{1}$ Department of Internal Medicine, Biomedical Research Institute, \\ Cancer Research Institute, Seoul National University Hospital, Seoul, Republic of Korea; \\ ${ }^{2}$ Department of Internal Medicine, Seoul Metropolitan Government Seoul National \\ University Boramae Medical Center, Seoul, Republic of Korea; \\ ${ }^{3}$ Department of Internal Medicine, Kyungpook National University Hospital, Daegu, Republic of Korea; \\ ${ }^{4}$ Department of Internal Medicine, Asan Medical Center, \\ University of Ulsan College of Medicine, Seoul, Republic of Korea; \\ ${ }^{5}$ Department of Internal Medicine, Chonnam National University, Hwasun Hospital, Hwasun, Republic of Korea; \\ ${ }^{6}$ Department of Internal Medicine, Seoul National University, Bundang Hospital, Seongnam, Republic of Korea; \\ ${ }^{7}$ Department of Internal Medicine, Yonsei University, Severance Hospital, Seoul, Republic of Korea; \\ ${ }^{8}$ Department of Internal Medicine, Chosun University Hospital, Gwangju, Republic of Korea; \\ ${ }^{9}$ Department of Internal Medicine, Inje University, Haeundae Paik Hospital, Busan, Republic of Korea
}

\begin{abstract}
Background/Aim: Droplet digital polymerase chain reaction (ddPCR) is an exact method of measuring nucleic acids. The aim of this prospective study was to evaluate minimal residual disease (MRD) using ddPCR in chronic myeloid leukemia (CML) patients. Patients and Methods: Between May 2013 and November 2014, CML patients treated with nilotinib were enrolled in our study.
\end{abstract}

This article is freely accessible online.

\footnotetext{
*These Authors contributed equally to this work. †These Authors contributed equally as corresponding authors.
}

Correspondence to: Inho Kim, Department of Internal Medicine, Seoul National University Hospital, Cancer Research Institute, Seoul National University, College of Medicine, 101, Daehak-ro, Jongno-gu, Seoul 03080, Republic of Korea. Tel: +82 220720834, Fax: +82 27642199, e-mail: ihkimmd@snu.ac.kr and Sang-Kyun Sohn, Department of Internal Medicine, Kyungpook National University Hospital, 130 Dongdeok-ro, Jung-gu, Daegu 41944, Republic of Korea. Tel: +82 532005587, Fax: +82 534262046, email: sksohn@knu.ac.kr

Key Words: Chronic myeloid leukemia, droplet digital polymerase chain reaction, minimal residual disease, complete molecular response, treatment outcome.
$B C R / A B L 1$ transcripts levels were evaluated using ddPCR at the first time of complete molecular response (CMR). We enrolled 15 patients from 7 Institutions. The treatment period and median follow-up period were 45 months and 47 months, respectively. Results: Patients with a high level of $B C R / A B L 1$ transcript had a greater tendency to lose the CMR during the follow-up period $(p=0.095)$. In addition, patients with a low level of BCR/ABL1 transcript showed a longer duration of CMR compared to those with a high level $(p=0.032)$. Conclusion: We found that ddPCR is a sensitive method for detecting MRD and that MRD could affect the duration of the treatment response.

Chronic myeloid leukemia (CML) is cytogenetically characterized by the translocation of $\mathrm{t}(9 ; 22)$ ( $\mathrm{q} 34 ; \mathrm{q} 11.2)$, which produces the $B C R / A B L 1$ fusion oncogene (1). Since the success of imatinib, the first targeted agent in human history, more effective tyrosine kinase inhibitors (TKIs), such as dasatinib and nilotinib have been introduced to the frontline treatment of CML and show a $76-82 \%$ major molecular response rate $(2,3)$. CML is now thought to be a life-long disease with a 5-year overall survival rate>90\% (4).

Previous reports have demonstrated that achievement of an early molecular response is a strong predictive marker of improved outcomes (5). Therefore, the European LeukemiaNet 
guidelines recommended that the optimal response is a percentage of $B C R / A B L 1$ fusion transcript on the International Scale $\left(B C R / A B L 1^{\mathrm{IS}}\right)$ of $<10 \%$ at 3 months after initial treatment, followed by $<1 \%$ at 6 months and $0.1 \%$ at 12 months, using quantitative real-time polymerase chain reaction (qRT-PCR) (6). In addition, recent evidence has shown that achievement of a deep molecular response (DMR), including $\mathrm{MR}^{4}$ $\left(B C R / A B L 1^{\mathrm{IS}} \leq 0.01 \%\right)$ or $\mathrm{MR}^{4.5}\left(B C R / A B L 1^{\mathrm{IS}} \leq 0.0032 \%\right)$, is a surrogate marker of favorable survival and treatment-free remission (7). Currently, selected patients who achieve a DMR can attempt to discontinue TKIs to improve their quality of life and alleviate financial strain (8). Although qRT-PCR is generally used for regular monitoring, additional sensitive methods are needed to detect minimal residual disease (MRD).

Droplet digital polymerase chain reaction (ddPCR) allows the precise quantification of nucleic acids. Due to its positive outcomes, it has been used to detect MRD of hematologic disorders (9). In CML, ddPCR has been validated for the exact measurement of $B C R / A B L 1$ fusion transcripts (10).

We hypothesized that ddPCR would be more sensitive compared to conventional qRT-PCR for measuring oncotranscript levels in patients with a DMR. Therefore, the aim of this study was to evaluate MRD using ddPCR in nilotinib-treated CML patients who firstly achieved a complete molecular response (CMR) as assessed by qRTPCR. We also evaluated the relationship between ddPCR positivity and patient prognosis.

\section{Patients and Methods}

Patient characteristics. From May 2013 to November 2014, we prospectively enrolled Philadelphia chromosome (Ph)-positive CML chronic phase patients who achieved a CMR during treatment with nilotinib. All patients were treated with nilotinib $300 \mathrm{mg}$ twice daily as the first-line target therapy.

Inclusion and exclusion criteria were the same as those in the openlabel, multi-institutional phase 4 ENESTKorea trial (11). This study included adult patients diagnosed as Ph-positive CML chronic phase. The diagnosis was confirmed using cytogenetic analysis of at least 20 bone marrow metaphase cells within 6 months before enrollment. The exclusion criteria were as follows: i) CML with atypical $B C R / A B L 1$ transcripts (transcripts other than e13a2 or e14a2, ii) previous treatment with myelosuppressive agents except for hydroxyurea and anagrelide, iii) previous treatment with TKI for over two weeks, iv) previous hematopoietic stem cell transplantation, v) previous irradiation involving $25 \%$ or more of the bone marrow tissue, vi) cytopathologicallyconfirmed central nervous system involvement of CML, vii) Eastern Cooperative Oncology Group performance status $\geq 3$ (12), viii) cardiac abnormalities including: a) corrected QT interval $\geq 480$ milliseconds on electrocardiogram, b) complete left bundle branch block, c) permanent pacemaker implantation, d) congenital long QT syndrome, e) history of tachyarrhythmia requiring treatment, f) clinically significant resting bradycardia, g) history of acute coronary syndrome within 12 months, and $\mathrm{h}$ ) decompensated congestive heart failure, ix) organ dysfunction defined by: a) total serum bilirubin levels $\geq 1.5 \times$ the upper limit of the normal range (ULN), b) creatinine $\geq 1.5 \times U L N, c)$ aspartate or alanine aminotransferase $\geq 2.5 \times \mathrm{ULN}, \mathrm{d}$ ) amylase or lipase $\geq 1.5 \times \mathrm{ULN}$ and e) alkaline phosphatase $\geq 2.5 \times$ ULN not directly related to the CML, $x$ ) Active and uncontrolled malignancy other than CML, xi) uncontrolled hypertension and/or diabetes, xii) active and uncontrolled infection, xiii) major surgery within two weeks or incomplete recovery from the previous surgery, xiv) congenital or acquired bleeding tendency, $\mathrm{xv}$ ) Impaired gastrointestinal absorption, xvi) history of small bowel resection or bypass surgery, xvii) history of acute pancreatitis within 12 months or chronic pancreatitis, xviii) concomitant administration of strong irreplaceable CYP3A4 inhibitors or inducers, QT prolonging agents, or coumarin derivatives, and xix) any other uncontrolled medical conditions that would present substantial safety risks or compromise compliance with the study treatment. Among the patients enrolled in the ENESTKorea trial (11), we selected patients who achieved a CMR during the follow-up period and in whom we could evaluate the level of $B C R / A B L 1$ fusion transcripts using ddPCR at the time of firstly achieving CMR. CMR was defined as an undetectable $B C R / A B L 1$ transcript level by qRT-PCR (13). During the follow-up period, all patients were evaluated, and $B C R / A B L 1$ fusion transcripts were quantified and standardized to $B C R / A B L I^{\mathrm{IS}}$ by qRT-PCR performed at the central laboratory (BML, Daejeon, South Korea) every 3 months. This study used the protocol of qRT-PCR in ENESTKorea trial (11). The qRT-PCR used in this study had a sensitivity of $\mathrm{MR}^{4.5}$.

Clinical information, including patient demographics, $B C R / A B L 1$ fusion transcript level, and adverse events (AEs), were collected through medical record reviews at each institution.

Measurement of BCR/ABL1 fusion transcript level-Quantitative RT$P C R$ analysis of the mRNA levels. The isolated total RNA was reverse-transcribed into first-strand cDNA using SuperScript ${ }^{\circledR}$ III First-Strand Synthesis (Invitrogen, Carlsbad, CA, USA) according to manufacturer's instruction. One $\mu \mathrm{g}$ of total RNA was included in the final reaction volume of $20 \mu$. The reaction mixture was incubated at $50^{\circ} \mathrm{C}$ for 50 minutes, then heated to $85^{\circ} \mathrm{C}$ for 5 minutes to stop the reaction, and was then stored at $-20^{\circ} \mathrm{C}$ until the next step. After reverse transcription, $2 \mu \mathrm{l}$ from the reverse transcription reaction was used as a template in each PCR reaction for the $B C R / A B L 1$ and $B C R$ amplification. PCR was performed in a total volume of $15 \mu \mathrm{L}$ using the SsoAdvanced ${ }^{\mathrm{TM}}$ Universal SYBR ${ }^{\circledR}$ Green Supermix (Bio Rad, Hercules, CA, USA) and CFX384 RealTime System thermocycler (Bio Rad). The amplification profile involved denaturation at $95^{\circ} \mathrm{C}$ for 30 seconds for 1 cycle and then denaturation at $95^{\circ} \mathrm{C}$ for 15 seconds and one step of annealing and elongation at $65^{\circ} \mathrm{C}$ for 30 seconds for 45 cycles. Following completion of the PCR, the amplification pattern of $B C R / A B L 1$ and $B C R$ was checked using a melting curve analysis. The threshold cycle number $\left(\mathrm{C}_{\mathrm{T}}\right)$ of each sample was used to determine the copy number and was compared to a corresponding standard curve generated with 7 different copy numbers (from $10^{6}$ to $10^{0}$ copies) for each recombinant plasmid, including the $B C R$ or $B C R / A B L 1$ amplified region. The primer set for $B C R / A B L 1$ was 5'GATGCTGACCAACTCGTGTG-3' for the forward and 5'AACGAAAAGGTTGGGGTCAT-3' for the reverse. The primer set for $B C R$ was 5'-TTCTGGACCACCTGAAAAGG-3' for the forward and 5'-TGCTCTGTCTCTTGCTGTCC-3' for the reverse.

Droplet generation. ddPCR was performed in a total volume of $20 \mu \mathrm{l}$ containing $10 \mu \mathrm{l}$ EvaGreen supermix ( $2 \times$, Bio-Rad Laboratories), each primer set (final concentration of $150 \mathrm{nM}$ ), DNase/RNase-free sterile water, and a variable volume of diluted cDNA $(40,20$, or $5 \mathrm{ng})$ to 


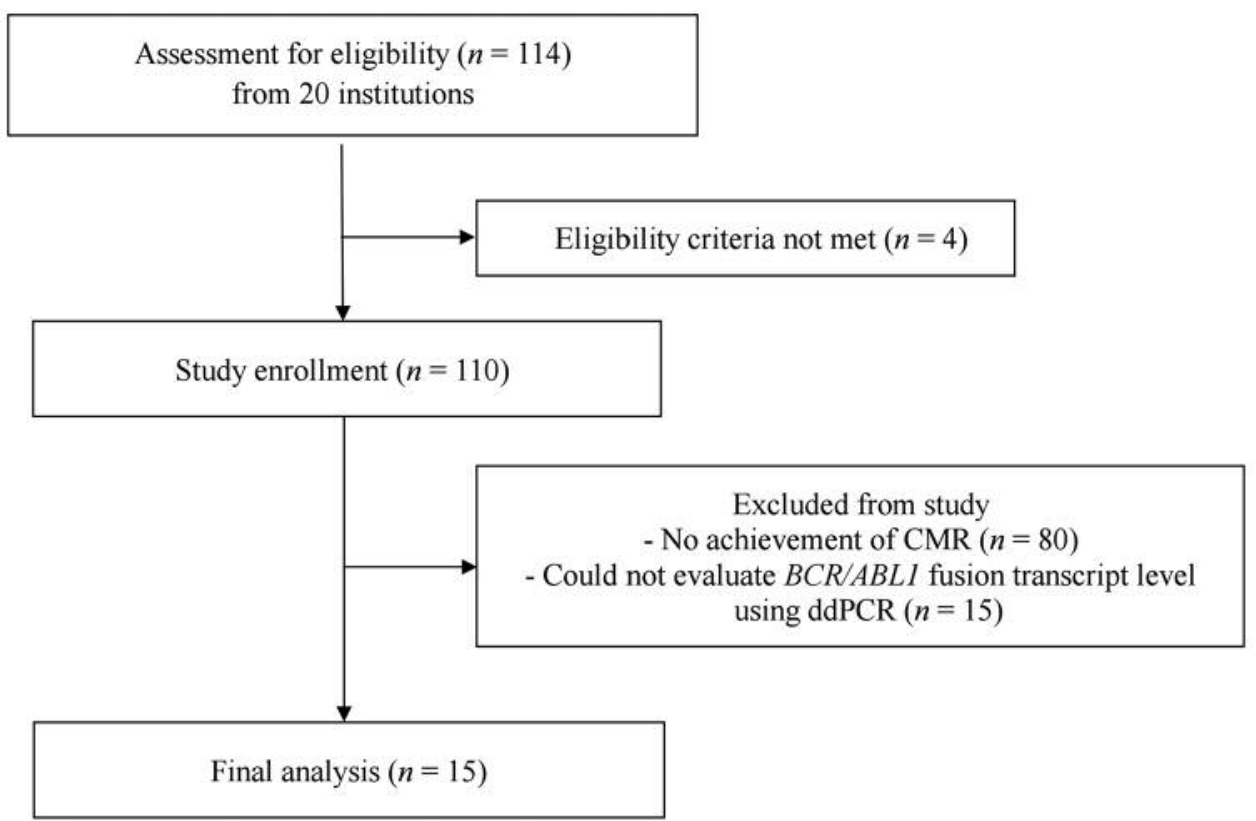

Figure 1. CONSORT flow diagram. CMR: Complete molecular response; ddPCR: droplet digital polymerase chain reaction.

achieve a higher sensitivity and to define the threshold. Primer sequences are as follows; $B C R$ forward primer: 5'-TTC TGG ACC ACC TGA AAA GG-3'; $B C R$ reverse primer: 5'-TGC TCT GTC TCT TGC TGT CC-3'; $B C R / A B L 1$ forward primer: 5'-GAT GCT GAC CAA CTC GTG TG-3'; BCR/ABL1 reverse primer: 5'-AAC GAA AAG GTT GGG GTC AT-3'. Each ddPCR mixture was loaded into each sample well of a DG8 droplet generator cartridge (Bio-Rad Laboratories), followed by the loading of $70 \mu$ droplet generation oil for EvaGreen (Bio-Rad Laboratories) into each oil well of the DG8 cartridge. The cartridge was placed inside a QX200 droplet generator (Bio-Rad Laboratories). When droplet generation was completed, approximately 20,000 droplets were generated in each droplet well. Droplets in each droplet well were transferred to a 96-well PCR plate (Bio-Rad Laboratories) and were sealed using a PX1 PCR plate sealer (Bio-Rad Laboratories) for 5 seconds at $180^{\circ} \mathrm{C}$ before thermal cycling. The PCR plate was placed in a deep-well C1000 Touch thermal cycler (Bio-Rad Laboratories) for amplification. Thermal cycling conditions were: i) 5 minutes at $95^{\circ} \mathrm{C}$, ii) 40 cycles of denaturation for 30 seconds at $95^{\circ} \mathrm{C}$ and iii) annealing/extension for 1 minute at $58^{\circ} \mathrm{C}$, and three final steps iv) at $4^{\circ} \mathrm{C}$ for 5 minutes, v) $90^{\circ} \mathrm{C}$ for 5 minutes, and vi) $4^{\circ} \mathrm{C}$ infinite hold. All PCR steps were conducted with a change of $2^{\circ} \mathrm{C} / \mathrm{s}$. A no template control and a positive control (cDNA synthesized from K562 total RNA) were included in each assay.

$d d P C R$. Following thermal cycling, the PCR plate including the droplets was loaded onto the QX200 droplet reader (Bio-Rad Laboratories), which identified the fluorescence intensity of each droplet for EvaGreen fluorophore, using a multi-pixel photon counter. This detector reads the droplets to identify those that do (+) or do not (-) contain a target gene by plotting fluorescence dropletby-droplet. We determined droplets to be positive ones only for samples whose fluorescence levels differed significantly from the back-ground fluorescence level. We used QuantaSoft software version 1.7.4 (Bio-Rad Laboratories) to determine the concentration of the target gene in copies/ $\mu$ l.

Statistical analysis. Comparisons of categorical variables were performed using Fisher's exact tests. The Kaplan-Meier method was used to analyze the period of treatment response. The duration of CMR was defined as the period of undetectable $B C R / A B L 1$ transcript $\left(B C R / A B L 1^{\mathrm{IS}}=0 \%\right)$ by qRT-PCR. The duration of $\mathrm{MR}^{4.5}$ was defined as the period from no detection of $B C R / A L B 1$ (i.e., the day ddPCR was performed) firstly to the loss of $\mathrm{MR}^{4.5}$ $\left(B C R / A B L 1^{\mathrm{IS}}=0.0032 \%\right)$ by qRT-PCR. The cut-off value of $B C R / A L B 1$ transcript level was the median value (3.6 copies/20 $\mu \mathrm{L}$ ) of the total level of $B C R / A B L 1$ transcripts measured using 40,20 , or 5ng of RNA (Table II).

Ethical considerations. The study protocol was reviewed and approved by the Institutional Review Board of each of the 7 hospitals and was in accordance with principles established by the Declaration of Helsinki for biomedical research (14). Informed consent was obtained from all patients for being included in the study.

\section{Results}

Patient characteristics. Between May 2013 and November 2014, 15 patients from 7 institutions who met the inclusion criteria were enrolled in this study (Figure 1 and Table I). The median follow-up period for a total of 110 patients was 22.7 months (range=0.1-54.2 months), and for the 80 patients who 
Table I. Baseline patient characteristics $(n=15)$.

\begin{tabular}{|c|c|c|c|c|c|c|}
\hline Patient & Gender & Age (years) & Treatment period (months) & Change to other drug & Cause of change & Loss of $\mathrm{MR}^{4.5}$ \\
\hline 1 & Male & 51 & 58 & Yes (imatinib) & $\mathrm{AE}$ (angina) & Yes \\
\hline 2 & Male & 58 & 43 & No & - & No \\
\hline 3 & Male & 43 & 53 & No & - & Yes \\
\hline 4 & Male & 47 & 41 & No & - & No \\
\hline 5 & Female & 52 & 48 & No & - & No \\
\hline 6 & Male & 63 & 45 & No & - & No \\
\hline 7 & Male & 77 & 45 & No & - & No \\
\hline 8 & Female & 44 & 43 & No & - & No \\
\hline 9 & Male & 54 & 41 & No & - & No \\
\hline 10 & Female & 38 & 42 & No & - & No \\
\hline 11 & Male & 83 & 39 & No & - & No \\
\hline 12 & Male & 64 & 54 & No & - & No \\
\hline 13 & Female & 58 & 44 & No & - & No \\
\hline 14 & Female & 56 & 47 & No & - & No \\
\hline 15 & Male & 64 & 45 & No & - & No \\
\hline
\end{tabular}

AE: Adverse event; $\mathrm{MR}^{4.5}$ : molecular response at 4.5-log reduction.

Table II. BCR/ABL1 transcript levels using ddPCR at IS 0\%.

\begin{tabular}{|c|c|c|c|c|c|}
\hline \multirow[t]{2}{*}{ Patient } & \multirow{2}{*}{$\begin{array}{c}B C R \text { level } \\
(\text { copies/20 } \mu \mathrm{l})\end{array}$} & \multirow{2}{*}{$\begin{array}{l}\text { Total } B C R / A B L 1 \text { level } \\
\quad(\text { copies } / 20 \mu \mathrm{l})\end{array}$} & \multicolumn{3}{|c|}{$B C R / A B L 1$ level $($ copies $/ 20 \mu \mathrm{l})$} \\
\hline & & & Input RNA (40 ng) & Input RNA (20 ng) & Input RNA (5 ng) \\
\hline 1 & 15,758 & 6.6 & 4.0 & 1.2 & 1.4 \\
\hline 2 & 18,836 & 2.2 & 0.0 & 0.0 & 2.2 \\
\hline 3 & 4,098 & 3.8 & 0.0 & 2.6 & 1.2 \\
\hline 4 & 10,728 & 3.6 & 3.6 & 0.0 & 0.0 \\
\hline 5 & 22,382 & 2.4 & 0.0 & 2.4 & 0.0 \\
\hline 6 & 2,434 & 4.0 & 1.2 & 0.0 & 2.8 \\
\hline 7 & 11,196 & 1.2 & 1.2 & 0.0 & 0.0 \\
\hline 8 & 11,860 & 6.8 & 1.2 & 1.2 & 4.4 \\
\hline 9 & 26,262 & 6.4 & 1.2 & 2.4 & 2.8 \\
\hline 10 & 31,024 & 2.6 & 1.2 & 0.0 & 1.4 \\
\hline 11 & 18,294 & 3.6 & 2.4 & 1.2 & 0.0 \\
\hline 12 & 34,140 & 3.6 & 1.2 & 2.4 & 0.0 \\
\hline 13 & 1,802 & 2.6 & 0.0 & 1.2 & 1.4 \\
\hline 14 & 9,908 & 1.2 & 1.2 & 0.0 & 0.0 \\
\hline 15 & 25,720 & 2.6 & 1.2 & 0.0 & 1.4 \\
\hline
\end{tabular}

ddPCR: Droplet digital polymerase chain reaction; IS: International Scale.

did not achieve CMR, it was 22.5 months (range=0.1-37.0 months), respectively. The median follow-up period for the 15 patients who were included in this study was 47 months (range=39-61 months). All patients received nilotinib at a starting dose of $300 \mathrm{mg}$ twice daily. Median patient age was 56 years (range $=38-83$ years). Ten $(66.7 \%)$ and five $(33.3 \%)$ patients were male and female, respectively.

ddPCR measurement. We measured the levels of $B C R / A B L 1$ and $B C R$ transcripts using ddPCR three times when CMR was firstly achieved, as verified by qRT-PCR (Table II). The median values of total $B C R / A B L 1$ and $B C R$ transcript levels were 3.6 copies $/ 20 \mu \mathrm{l}$ (range $=1.2-6.8$ copies $/ 20 \mu \mathrm{l}$ ) and 15,758 copies $/ 20 \mu \mathrm{l}$ (range $=1802-34140$ copies $/ 20 \mu \mathrm{l}$ ), respectively.

ddPCR results and treatment outcome. The median treatment and follow-up periods for the 15 patients were 45 months (range $=37-55$ months) and 47 months (range=39-61 months), respectively. Except for one patient who switched to imatinib 

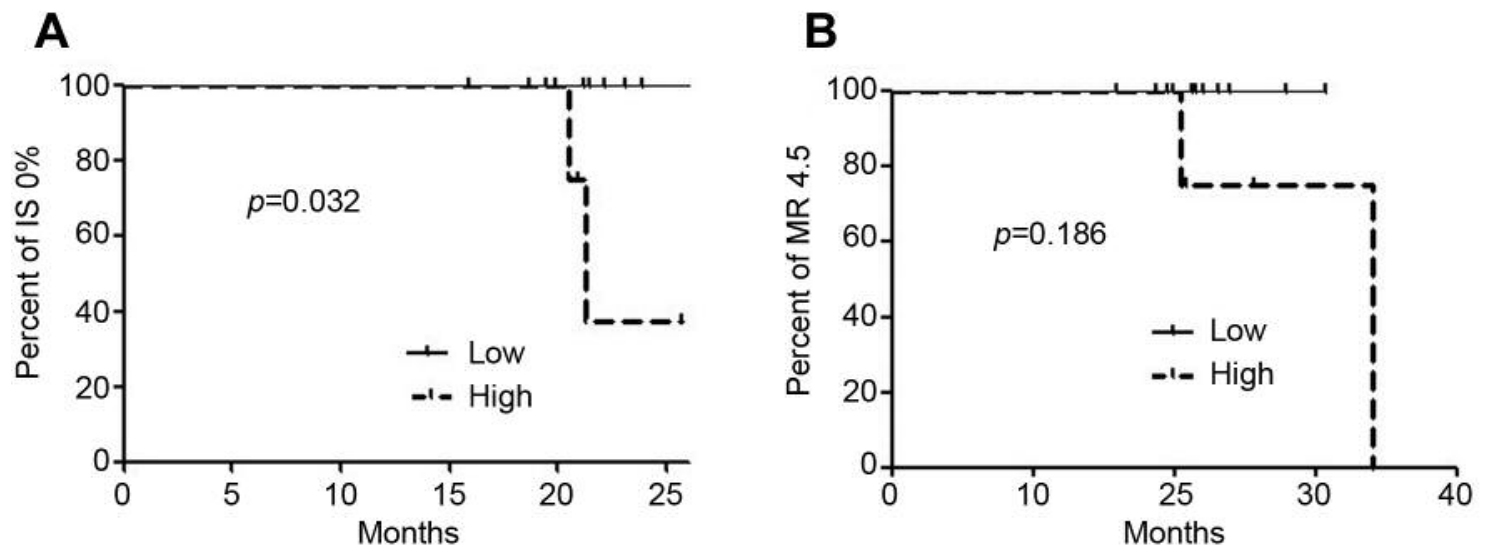

Figure 2. Kaplan Meier graphs. (A) The duration of complete molecular response depending on BCR/ABL1 transcript level (median: 3.6 copies/20 $\mu L)$ as measured by ddPCR. (B) Period of no BCR/ABL1 detection using qRT-PCR to loss of MR4.5. IS: International Scale; MR4.5: molecular response at 4.5-log reduction; ddPCR: droplet digital polymerase chain reaction; qRT-PCR: quantitative real-time polymerase chain reaction.

Table III. Tendency for loss of CMR during the follow-up period.

\begin{tabular}{|c|c|c|c|}
\hline & $\begin{array}{l}\text { Low } B C R / A B L 1 \text { level by } \\
\text { ddPCR at time of CMR } \\
(<3.6 \text { copies } / 20 \mu \mathrm{l})\end{array}$ & $\begin{array}{l}\text { High } B C R / A B L 1 \text { level by } \\
\text { ddPCR at time of CMR } \\
(\geq 3.6 \text { copies } / 20 \mu \mathrm{l})\end{array}$ & $p$-Value \\
\hline Loss of CMR by qRT-PCR & $0(0 \%)$ & $2(40 \%)$ & 0.095 \\
\hline No loss of CMR by qRT-PCR & $10(100 \%)$ & $3(60 \%)$ & \\
\hline
\end{tabular}

CMR: Complete molecular response; ddPCR: droplet digital polymerase chain reaction; qRT-PCR: quantitative real-time polymerase chain reaction.

37 months after initiation of nilotinib due to a nilotinib-induced cardiovascular event, 14 patients were treated with nilotinib continuously. During the follow-up period, all patients maintained a major molecular response $\left(B C R / A B L 1^{\mathrm{IS}} \leq 0.1 \%\right)$. Among 15 patients, 2 patients lost CMR during the follow-up period. One patient lost CMR after sustaining it over 21.3 months, and $0.002 \%$ of $B C R / A B L 1$ was detected by qRT-PCR. The other patient lost CMR, and $0.012 \%$ of $B C R / A B L 1$ was detected after sustaining it for 20.5 months. However, they did not lose MMR during the last follow-up period ( 9 months for one patient and 8 months for the other patient after the loss of CMR).

In subsequent analyses, we used the median value of total $B C R / A B L 1$ transcript levels (3.6 copies/20 $\mu \mathrm{l})$ as a cut-off value. Although patients with a high level ( $>3.6$ copies/20 $\mu \mathrm{l})$ of $B C R / A B L 1$ transcripts had a tendency to lose the CMR during the follow-up period, there was no significant difference in CMR loss between patients with a low level $(0 / 10,0 \%)$ versus a high level $(2 / 5,40 \%)(p=0.095$; Table III). CMR duration was prolonged in patients with a low level of $B C R / A B L 1$ transcripts, as measured by ddPCR (rate of sustained CMR at 2 years: $100 \%$ for low level versus $37.5 \%$ for high level, $p=0.032$; Figure 2A). However, there was no significant difference between groups from the day of the first CMR to the day of $\mathrm{MR}^{4.5}$ loss (rate of sustained $\mathrm{MR}^{4.5}$ at 2 years:100\% for low level versus $75.0 \%$ for high level, $p=0.186$; Figure 2B).

\section{Discussion}

MRD is considered very important in various cancers because a low or negative MRD after treatment is associated with a longer response duration and survival (15-17), and the achievement of a DMR predicts a better clinical outcome in CML patients (18). Due to the remarkable results of withdrawal clinical studies (i.e., STIM and TWISTER studies), the appropriate selection of patients with a "true" CMR is important for predicting the success of treatmentfree remission $(19,20)$.

Currently, qRT-PCR is the primary method for monitoring the TKI response and MRD and for predicting early relapse $(6,21)$. Although qRT-PCR is relatively sensitive, it has several limitations due to its poor standardization and laborintensiveness (22). To overcome these limitations, recent 
emerging technologies, such as next-generation sequencing, next-generation flow, and ddPCR, have been applied for precision medicine $(23,24)$. Among these, ddPCR is an advanced method with results that strongly correlate with those of qRT-PCR $(25,26)$. ddPCR enables the measurement of absolute copy numbers without requiring a reference standard curve $(9,10,27)$. Furthermore, it can detect nucleic acids with a sensitivity exceeding $10^{-6}$ and is less influenced by inhibitory substances, non-target RNA, and nonspecific amplification $(10,27)$. Because of these advantages, ddPCR has been used to evaluate circulating tumor DNA, mutations, and tumor burden in cancer research (28). ddPCR has also been used to detect MRD and predict prognosis in hematologic malignancy $(9,25)$. Therefore, ddPCR could be an optimal alternative modality for qRT-PCR; however, disadvantages of ddPCR, including its high cost, timeintensiveness, and limited data in the clinical setting, must be solved to allow its wider use (29).

Our results indicate that ddPCR could be a sensitive tool for detecting MRD as a complement to qRT-PCR. $B C R / A B L 1$ transcripts were detected in all patients by ddPCR even though a CMR state $\left(B C R / A B L 1^{\mathrm{IS}}=0 \%\right)$ was verified by qRT-PCR. In addition, we noted that the duration of CMR differed significantly depending on MRD, as detected by ddPCR at the time when CMR was firstly achieved. This finding suggests that a low MRD is an important factor for maintaining longer remission periods, consistent with the results of previous studies (18). However, because all our patients maintained a major molecular response during their treatment with TKIs, it is questionable whether an elevated $B C R / A B L 1$ transcript level detected by ddPCR is clinically meaningful as a treatment failure (6). Additionally, because of the superior treatment response to nilotinib, with an approximately $80 \%$ rate of complete cytogenetic response, all patients might maintain an optimal response during the follow-up period (30). Therefore, for an evaluation of long-term outcomes, further follow-up might be needed.

Additional limitations of this study were that we could not routinely use ddPCR for response monitoring every 3 months. Because ddPCR is not yet widely commercialized, frequent use of ddPCR was limited. In addition, some patients did not show homogeneous results according to the input RNA, which is also another limitation. The standardization of the quantitative measurement of $B C R / A B L 1$ by ddPCR has not yet been well-established. Therefore, there has been a concerted effort to obtain precise results with less false-positive droplets (e.g. using an adequate volume of cDNA) (26). Nevertheless, a previous study has shown that the false-positive rate can be $2 \%$ even when healthy donors are used (31). Therefore, further standardization and validation of the protocol are needed for a higher sensitivity of ddPCR.
Another limitation of our study was that sample size was small despite this being a multi-institution study. Therefore, a large-scale study is needed to confirm these results. Despite these limitations, to the best of our knowledge, this is the first study reporting a difference in outcomes depending on $B C R / A B L 1$ transcript level measured by ddPCR in CML patients with a CMR state.

In conclusion, we demonstrated the sensitivity of ddPCR for detecting MRD at the time of undetectable $B C R / A B L 1$ transcripts, as measured by qRT-PCR in CML patients. Additionally, the duration of CMR differed significantly depending on MRD at the time when the CMR was firstly achieved. Future large-scale trials and rigorous validation of the ddPCR are needed to widely use ddPCR for monitoring treatment response and for detecting MRD.

\section{Conflicts of Interest}

The Authors have declared that they have no conflicts of interest.

\section{Authors' Contributions}

HP, DYS, IK and SKS designed the research study. YK, JHL, KHL, DYK, HJK, JSA, JOL, SMB, JWC, SGP, SP, YJL and SYA conducted the study and collected the data. HP, DYS and IK analyzed the data. HP, DYS, IK and SKS wrote the paper. All authors read and approved the final manuscript.

\section{Acknowledgements}

KI and SSK contributed equally to this study as corresponding authors. This work was funded by Novartis Pharmaceuticals Corporation (CAMN107AKR11T).

\section{References}

1 Kujawski LA and Talpaz M: The role of interferon-alpha in the treatment of chronic myeloid leukemia. Cytokine Growth Factor Rev 18(5-6): 459-471, 2007. PMID: 17703986. DOI: 10.1016/ j.cytogfr.2007.06.015

2 Cortes JE, Jones D, O'Brien S, Jabbour E, Ravandi F, Koller C, Borthakur G, Walker B, Zhao W, Shan J and Kantarjian H: Results of dasatinib therapy in patients with early chronic-phase chronic myeloid leukemia. J Clin Oncol 28(3): 398-404, 2010. PMID: 20008620. DOI: 10.1200/JCO.2009.25.4920

3 Cortes JE, Jones D, O'Brien S, Jabbour E, Konopleva M, Ferrajoli A, Kadia T, Borthakur G, Stigliano D, Shan J and Kantarjian H: Nilotinib as front-line treatment for patients with chronic myeloid leukemia in early chronic phase. J Clin Oncol 28(3): 392-397, 2010. PMID: 20008621. DOI: 10.1200/JCO.2009.25.4896

4 Hochhaus A, Saglio G, Hughes TP, Larson RA, Kim DW, Issaragrisil S, le Coutre PD, Etienne G, Dorlhiac-Llacer PE, Clark RE, Flinn IW, Nakamae H, Donohue B, Deng W, Dalal D, Menssen HD and Kantarjian HM: Long-term benefits and risks of frontline nilotinib vs imatinib for chronic myeloid leukemia in chronic phase: 5-year update of the randomized enestnd trial. Leukemia 30(5): 1044-1054, 2016. PMID: 26837842. DOI: 10.1038/leu.2016.5 
5. Branford S, Kim DW, Soverini S, Haque A, Shou Y, Woodman RC, Kantarjian HM, Martinelli G, Radich JP, Saglio G, Hochhaus A, Hughes TP and Muller MC: Initial molecular response at 3 months may predict both response and event-free survival at 24 months in imatinib-resistant or -intolerant patients with philadelphia chromosome-positive chronic myeloid leukemia in chronic phase treated with nilotinib. J Clin Oncol 30(35): 4323-4329, 2012. PMID: 23109697. DOI: 10.1200/ JCO .2011 .40 .5217

6 Baccarani M, Deininger MW, Rosti G, Hochhaus A, Soverini S, Apperley JF, Cervantes F, Clark RE, Cortes JE, Guilhot F, Hjorth-Hansen H, Hughes TP, Kantarjian HM, Kim DW, Larson RA, Lipton JH, Mahon FX, Martinelli G, Mayer J, Muller MC, Niederwieser D, Pane F, Radich JP, Rousselot P, Saglio G, Saussele S, Schiffer C, Silver R, Simonsson B, Steegmann JL, Goldman JM and Hehlmann R: European leukemianet recommendations for the management of chronic myeloid leukemia: 2013. Blood 122(6): 872-884, 2013. PMID: 23803709. DOI: 10.1182/blood-2013-05-501569

7 Mahon FX and Etienne G: Deep molecular response in chronic myeloid leukemia: The new goal of therapy? Clin Cancer Res 20(2): 310-322, 2014. PMID: 24166905. DOI: 10.1158/10780432.CCR-13-1988

8 Flynn KE and Atallah E: Quality of life and long-term therapy in patients with chronic myeloid leukemia. Curr Hematol Malig Rep 11(2): 80-85, 2016. PMID: 26879546. DOI: 10.1007/s11899-0160306-5

9 Drandi D, Kubiczkova-Besse L, Ferrero S, Dani N, Passera R, Mantoan B, Gambella M, Monitillo L, Saraci E, Ghione P, Genuardi E, Barbero D, Omede P, Barberio D, Hajek R, Vitolo U, Palumbo A, Cortelazzo S, Boccadoro M, Inghirami G and Ladetto M: Minimal residual disease detection by droplet digital pcr in multiple myeloma, mantle cell lymphoma, and follicular lymphoma: A comparison with real-time pcr. J Mol Diagn 17(6): 652-660, 2015. PMID: 26319783. DOI: 10.1016/j.jmoldx.2015.05.007

10 Jennings LJ, George D, Czech J, Yu M and Joseph L: Detection and quantification of bcr-abl1 fusion transcripts by droplet digital pcr. J Mol Diagn 16(2): 174-179, 2014. PMID: 24389534. DOI: $10.1016 /$ j.jmoldx.2013.10.007

11 Shin J, Koh Y, Yoon SH, Cho JY, Kim DY, Lee KH, Kim HJ, Ahn JS, Kim YK, Park J, Sohn SK, Moon JH, Lee YJ, Yoon S, Lee JO, Cheong JW, Kim KH, Kim SH, Kim HG, Kim H, Nam SH, Do YR, Park SG, Park SK, Bae SH, Song HH, Shin DY, Oh D, Kim MK, Jung CW, Park S and Kim I: A phase 4 study of nilotinib in korean patients with philadelphia chromosomepositive chronic myeloid leukemia in chronic phase: Enestkorea. Cancer Med 7(5): 1814-1823, 2018. PMID: 29577674. DOI: $10.1002 / \mathrm{cam} 4.1450$

12 Oken MM, Creech RH, Tormey DC, Horton J, Davis TE, McFadden ET and Carbone PP: Toxicity and response criteria of the eastern cooperative oncology group. Am J Clin Oncol 5(6): 649-655, 1982. PMID: 7165009.

13 Press RD: Major molecular response in CML patients treated with tyrosine kinase inhibitors: The paradigm for monitoring targeted cancer therapy. Oncologist 15(7): 744-749, 2010. PMID: 20566700. DOI: 10.1634/theoncologist.2010-0055

14 World Medical Association Declaration of Helsinki: Ethical principles for medical research involving human subjects. Jama 310(20): 2191-2194, 2013. PMID: 24141714. DOI: 10.1001/ jama.2013.281053
15 Bottcher S, Ritgen M, Fischer K, Stilgenbauer S, Busch RM, Fingerle-Rowson G, Fink AM, Buhler A, Zenz T, Wenger MK, Mendila M, Wendtner CM, Eichhorst BF, Dohner H, Hallek MJ and Kneba M: Minimal residual disease quantification is an independent predictor of progression-free and overall survival in chronic lymphocytic leukemia: A multivariate analysis from the randomized gcllsg cll8 trial. J Clin Oncol 30(9): 980-988, 2012. PMID: 22331940. DOI: 10.1200/JCO.2011.36.9348

16 Venditti A, Buccisano F, Del Poeta G, Maurillo L, Tamburini A, Cox C, Battaglia A, Catalano G, Del Moro B, Cudillo L, Postorino M, Masi M and Amadori S: Level of minimal residual disease after consolidation therapy predicts outcome in acute myeloid leukemia. Blood 96(12): 3948-3952, 2000. PMID: 11090082.

17 Thompson PA, Tam CS, O'Brien SM, Wierda WG, Stingo F, Plunkett W, Smith SC, Kantarjian HM, Freireich EJ and Keating MJ: Fludarabine, cyclophosphamide, and rituximab treatment achieves long-term disease-free survival in ighv-mutated chronic lymphocytic leukemia. Blood 127(3): 303-309, 2016. PMID: 26492934. DOI: 10.1182/blood-2015-09-667675

18 Hehlmann R, Muller MC, Lauseker M, Hanfstein B, Fabarius A, Schreiber A, Proetel U, Pletsch N, Pfirrmann M, Haferlach C, Schnittger S, Einsele H, Dengler J, Falge C, Kanz L, Neubauer A, Kneba M, Stegelmann F, Pfreundschuh M, Waller CF, Spiekermann K, Baerlocher GM, Ehninger G, Heim D, Heimpel H, Nerl C, Krause SW, Hossfeld DK, Kolb HJ, Hasford J, Saussele $\mathrm{S}$ and Hochhaus A: Deep molecular response is reached by the majority of patients treated with imatinib, predicts survival, and is achieved more quickly by optimized high-dose imatinib: Results from the randomized CML-study iv. J Clin Oncol 32(5): 415-423, 2014. PMID: 24297946. DOI: 10.1200/JCO.2013.49.9020

19 Mahon FX, Rea D, Guilhot J, Guilhot F, Huguet F, Nicolini F, Legros L, Charbonnier A, Guerci A, Varet B, Etienne G, Reiffers $\mathrm{J}$ and Rousselot P: Discontinuation of imatinib in patients with chronic myeloid leukaemia who have maintained complete molecular remission for at least 2 years: The prospective, multicentre stop imatinib (stim) trial. Lancet Oncol 11(11): 10291035, 2010. PMID: 20965785. DOI: 10.1016/S1470-2045 (10)70233-3

20 Ross DM, Branford S, Seymour JF, Schwarer AP, Arthur C, Yeung DT, Dang P, Goyne JM, Slader C, Filshie RJ, Mills AK, Melo JV, White DL, Grigg AP and Hughes TP: Safety and efficacy of imatinib cessation for CML patients with stable undetectable minimal residual disease: Results from the twister study. Blood 122(4): 515-522, 2013. PMID: 23704092. DOI: 10.1182/blood-2013-02-483750

21 Olavarria E, Kanfer E, Szydlo R, Kaeda J, Rezvani K, Cwynarski K, Pocock C, Dazzi F, Craddock C, Apperley JF, Cross NC and Goldman JM: Early detection of bcr-abl transcripts by quantitative reverse transcriptase-polymerase chain reaction predicts outcome after allogeneic stem cell transplantation for chronic myeloid leukemia. Blood 97(6): 1560-1565, 2001. PMID: 11238091. DOI: 10.1182/blood.v97.6.1560

22 Radich JP: How I monitor residual disease in chronic myeloid leukemia. Blood 114(16): 3376-3381, 2009. PMID: 19661271. DOI: $10.1182 /$ blood-2009-02-163485

23 Flores-Montero J, Sanoja-Flores L, Paiva B, Puig N, GarciaSanchez O, Bottcher S, van der Velden VHJ, Perez-Moran JJ, Vidriales MB, Garcia-Sanz R, Jimenez C, Gonzalez M, MartinezLopez J, Corral-Mateos A, Grigore GE, Fluxa R, Pontes R, 
Caetano J, Sedek L, Del Canizo MC, Blade J, Lahuerta JJ, Aguilar C, Barez A, Garcia-Mateo A, Labrador J, Leoz P, Aguilera-Sanz C, San-Miguel J, Mateos MV, Durie B, van Dongen JJM and Orfao A: Next generation flow for highly sensitive and standardized detection of minimal residual disease in multiple myeloma. Leukemia 31(10): 2094-2103, 2017. PMID: 28104919. DOI: 10.1038/leu.2017.29

24 Ladetto M, Bruggemann M, Monitillo L, Ferrero S, Pepin F, Drandi D, Barbero D, Palumbo A, Passera R, Boccadoro M, Ritgen M, Gokbuget N, Zheng J, Carlton V, Trautmann H, Faham $M$ and Pott C: Next-generation sequencing and real-time quantitative pcr for minimal residual disease detection in b-cell disorders. Leukemia 28(6): 1299-1307, 2014. PMID: 24342950. DOI: $10.1038 /$ leu.2013.375

25 Wang WJ, Zheng CF, Liu Z, Tan YH, Chen XH, Zhao BL, Li GX, Xu ZF, Ren FG, Zhang YF, Chang JM and Wang HW: Droplet digital pcr for bcr/abl(p210) detection of chronic myeloid leukemia: A high sensitive method of the minimal residual disease and disease progression. Eur J Haematol 101(3): 291-296, 2018. PMID: 29691899. DOI: 10.1111/ejh.13084

26 Alikian M, Whale AS, Akiki S, Piechocki K, Torrado C, Myint T, Cowen S, Griffiths M, Reid AG, Apperley J, White H, Huggett JF and Foroni L: RT-QPCR and RT-digital PCR: A comparison of different platforms for the evaluation of residual disease in chronic myeloid leukemia. Clin Chem 63(2): 525-531, 2017. PMID: 27979961. DOI: 10.1373/clinchem.2016.262824

27 Takamatsu H: Comparison of minimal residual disease detection by multiparameter flow cytometry, ASO-qPCR, droplet digital PCR, and deep sequencing in patients with multiple myeloma who underwent autologous stem cell transplantation. J Clin Med 6(10), 2017. PMID: 28946710. DOI: 10.3390/jcm6100091
28 van Ginkel JH, Huibers MMH, van Es RJJ, de Bree R and Willems SM: Droplet digital PCR for detection and quantification of circulating tumor DNA in plasma of head and neck cancer patients. BMC Cancer 17(1): 428, 2017. PMID: 28629339. DOI: $10.1186 / \mathrm{s} 12885-017-3424-0$

29 Verhaegen B, De Reu K, De Zutter L, Verstraete K, Heyndrickx $\mathrm{M}$ and Van Coillie E: Comparison of droplet digital PCR and qPCR for the quantification of shiga toxin-producing Escherichia coli in bovine feces. Toxins (Basel) 8(5), 2016. PMID: 27213452. DOI: 10.3390/toxins8050157

30 Saglio G, Kim DW, Issaragrisil S, le Coutre P, Etienne G, Lobo C, Pasquini R, Clark RE, Hochhaus A, Hughes TP, Gallagher N, Hoenekopp A, Dong M, Haque A, Larson RA and Kantarjian HM: Nilotinib versus imatinib for newly diagnosed chronic myeloid leukemia. N Engl J Med 362(24): 2251-2259, 2010. PMID: 20525993. DOI: 10.1056/NEJMoa0912614

31 Franke G-N, Maier J, Tzonev S, Shelton DN, Cross M, Wildenberger K, Niederwieser D and Lange T: Increasing the sensitivity of bcr-abl monitoring by digital pcr by reducing the background noise. Blood 128: 3085, 2016.
Received July 10, 2019

Revised July 21, 2019

Accepted July 22, 2019 